\title{
Adult growth hormone deficiency treatment with a combination of growth hormone and insulin- like growth factor- 1 resulting in elevated sustainable insulin-like growth factor-1 and insulin-like growth factor binding protein 3 plasma levels: a case report
}

Eric R Braverman ${ }^{1,3}$, Abdalla Bowirrat ${ }^{2}$, Uma J Damle ${ }^{3}$, Swetha Yeldandi ${ }^{3}$, Thomas JH Chen ${ }^{4}$, Margaret Madigan ${ }^{5}$, Mallory Kerner ${ }^{3}$, Stanley X Huang ${ }^{3}$, Stella Savarimuthu ${ }^{3}$, Kenneth Blum ${ }^{3,5,6^{*}}$

\begin{abstract}
Introduction: Adult Growth hormone Deficiency is a well known phenomenon effecting both males and females. Adult Growth Hormone Deficiency is marked by a number of neuropsychiatric, cognitive performance, cardiac, metabolic, muscular, and bone symptoms and clinical features. There is no known standardized acceptable therapeutic modality to treat this condition. A recent meta-analysis found that after 16 years of Growth Hormone replacement therapy a large proportion of the patients still had Growth Hormone associated symptoms especially related to executive functioning. A major goal is to increase plasma levels of both insulin-like growth factor (insulin-like growth factor-1) and insulin-like growth factor binding protein 3.
\end{abstract}

Case Presentation: We report a case of a 45-year-old caucasian woman with early ovarian failure for 2 years and amenorrhea since the age of 43, who presented with Adult Growth Hormone Deficiency and an IGF-1 of $126 \mathrm{ng} / \mathrm{mL}$. Since her insulin-like growth factor-1 was lowest at $81 \mathrm{ng} / \mathrm{mL}$, she was started on insulin-like growth factor-1 Increlex at $0.2 \mathrm{mg}$ at bedtime, which immediately raised her insulin-like growth factor- 1 levels to $130 \mathrm{ng} / \mathrm{mL}$ within 1 month, and $193 \mathrm{ng} / \mathrm{mL}, 249 \mathrm{ng} / \mathrm{mL}$, and $357 \mathrm{ng} / \mathrm{mL}$, after 3, 4, and 5 months, respectively, thereafter. Her insulin-like growth factor binding protein 3 continued to decrease. It was at this point when we added back the Growth Hormone and increased her Increlex dosage to 1.3 - $1.5 \mathrm{mg}$ that her insulin-like growth factor binding protein 3 began to increase.

Conclusion: It appears that in some patients with Adult Growth Hormone Deficiency, insulin-like growth factor-1 elevation is resistant to direct Growth Hormone treatment. Furthermore, the binding protein may not rise with insulin-like growth factor-1. However, a combination of Growth Hormone and insulin-like growth factor-1 treatment may be a solution.

\section{Introduction}

Adult Growth Hormone Deficiency (AGHD) is a well known phenomenon effecting both males and females. AGHD is marked by a number of neuropsychiatric, cognitive performance, cardiac, metabolic, muscular, and

\footnotetext{
* Correspondence: drd2gene@aol.com

${ }^{3}$ Department of Clinical Neurology, PATH Foundation NY, NewYork, NY, USA

Full list of author information is available at the end of the article
}

bone symptoms and clinical features [1]. In one study it was found that after one year of growth hormone (GH) replacement therapy in ovarian cancer patients among others, the mean value of all tumor markers remained within the normal range and there was no significant increase within the normal range either. This finding was accompanied by an increase of insulin-like growth factor (IGF-1) plasma levels [2]. 
However, the use of $\mathrm{GH}$ replacement therapy has not always resulted in consistent increases of IGF-1 in AGHD patients. The mechanism of this inconsistency has been studied by De Gennaro et al. [3]. In a series of experiments they investigated the effect of thyroid hormone deficiency and GH treatment on hypothalamic GH-releasing hormone (GHRH)/somatostatin (SS) concentrations, GHRH/SS mRNA levels, and plasma GH and somatomedin-C (IGF-1) concentrations in rats made deficient by exposing dams with propylthiouracil in the drinking water since the day of parturition. Treatment of hypothyroid rats with $\mathrm{GH}$ for 14 days completely restored hypothalamic GHRH content and reversed the increase in GHRH mRNA, but did not alter plasma IGF-1 concentrations. These data indicate that, in hypothyroid rats, the changes in hypothalamic GHRH content and gene expression are due to the GH deficiency ensuing from the hypothyroid state. Failure of the $\mathrm{GH}$ treatment to increase plasma IGF-1 indicates that the feedback regulation on GHRH neurons is operated by circulating $\mathrm{GH}$ and/or perhaps tissue but not plasma IGF-1 concentrations. Presence of low plasma IGF-1 concentrations would be directly related to thyroid hormone deficiency in this case but consistent methods for augmenting its levels in AGHD are unfortunately lacking. There is no known standardized acceptable therapeutic modality to treat this condition.

While there is a plethora of literature from meta-analysis showing the medical benefits of $\mathrm{GH}$ replacement therapy in cardiovascular disease, cancer risk, HIV, bone mineral density, fibromyalgia, head trauma, brain processing speed among others [3-10], there remains controversy as to what actually constitutes AGHD.

Previously, a number of hormonal test levels had to be lowered or raised as new research supported specific level changes (that is, PTH, TSH). In adults, a similar problem has arisen for an appropriate reference standard for IGF-1 and AGHD. Falletti et al. [3] in their meta-analysis suggested that the notion of IGF-1 plasma levels to be an independent diagnostic marker in AGHD is controversial. Many endocrinology studies link low IGF-1 plasma levels with low levels of other anterior pituitary hormones, that is, LH, FSH, and TSH [11]. It is noteworthy that low IGF-1 between 84 and $100 \mathrm{u} / \mathrm{l}$ with other anterior pituitary deficiencies has been considered sufficient evidence for GH therapy. However, we recently reported that IGF-1 deficiencies occur independently of comorbid deficiencies of $\mathrm{LH}$, $\mathrm{FSH}$, and TSH [12].

We report on a case where a woman with early ovarian failure, accompanied by seemingly low IGF-1 plasma levels, had severe comorbid symptoms which worsened as her IGF-1 levels continued to fall independent of anterior pituitary hormone deficiency assessment. We show that a combination of $\mathrm{GH}$ and IGF-1 replacement therapy to increase both IGF-1 and IGF-BP3 plasma levels may indeed be an important novel therapeutic modality to treat AGHD independent of targeting anterior pituitary hormone deficiencies.

\section{Case presentation}

A 45-year-old Caucasian woman with early ovarian failure of two years duration came to our clinic. She was diagnosed with AGHD with a IGF-1 plasma level of 126 $\mathrm{ng} / \mathrm{mL}$. At entrance to our program she was on Human Growth Hormone at a dosage of $0.2 \mathrm{mg}$. Follow-up blood analysis revealed that instead of rising, her IGF-1 level continued to fall and she felt her symptoms worsening. These symptoms included abdominal distention and bloating, sleeping problems, depression, nervousness, loss of muscle mass, decreased bone density and weight change (increase). Interestingly, her IGF-BP3 level was also low.

During the course of treatment, following treatment with Norditropin ${ }^{\oplus}$ (somatropin (rDNA origin)) by injection at $0.45 \mathrm{mg}$, her $\mathrm{GH}$ level continued to drop. The dosage level was increased to 0.6 to $0.7 \mathrm{mg}$ and she experienced rapid weight gain. At that point the dosage level was decreased to $0.5 \mathrm{mg}$. Subsequent to this treatment we determined that while her IGF-1 level increased, her IGF-BP3 level decreased and her symptoms worsened, especially the rapid weight gain. The Norditropin ${ }^{\bullet}$ regimen was terminated on 6 August 2009. On 6 May 2009, we found that her IGF-1 plasma level was at a low level of $81 \mathrm{ng} / \mathrm{ml}$. (see Figure 1).

At this juncture one of us (ERB) considered the use of Increlex $^{\odot}$ (a mecasermin (rDNA origin) injection). This agent is an aqueous solution for injection containing human insulin-like growth factor-1 (rhIGF-1) produced by recombinant DNA technology. IGF-1 consists of 70 amino acids in a single chain with three intramolecular disulfide bridges and a molecular weight of 7649 daltons. The amino acid sequence of the product is identical to that of endogenous human IGF-1. The rhIGF-1 protein is synthesized in bacteria (Escherichia coli) that have been modified by the addition of the gene for human IGF-1. This agent was started at $0.2 \mathrm{mg}$ at bedtime which we found to raise her IGF-1 level to $130 \mathrm{ng} /$ $\mathrm{ml}$ within one month and, as observed in Figure 1, increased by 6 August 2009 to $193 \mathrm{ng} / \mathrm{ml}$, then to 249 $\mathrm{ng} / \mathrm{ml}$ on 5 September 2009, and finally on 1 January 2010 it was at a high of $395 \mathrm{ng} / \mathrm{ml}$. Surprisingly her IGF-BP3 plasma levels continued to decrease to $2.5 \mathrm{ng} /$ ml. On 23 November 2009 we re-administered Norditropin $^{\odot}$ in combination with an increased amount of Increlex ${ }^{\oplus}$ between 1.3 and $1.5 \mathrm{mg}$. Subsequent to this treatment while her IGF-1 level was maintained at a high level (373 to $395 \mathrm{ng} / \mathrm{ml}$ ) her IGF-BP3 began to 


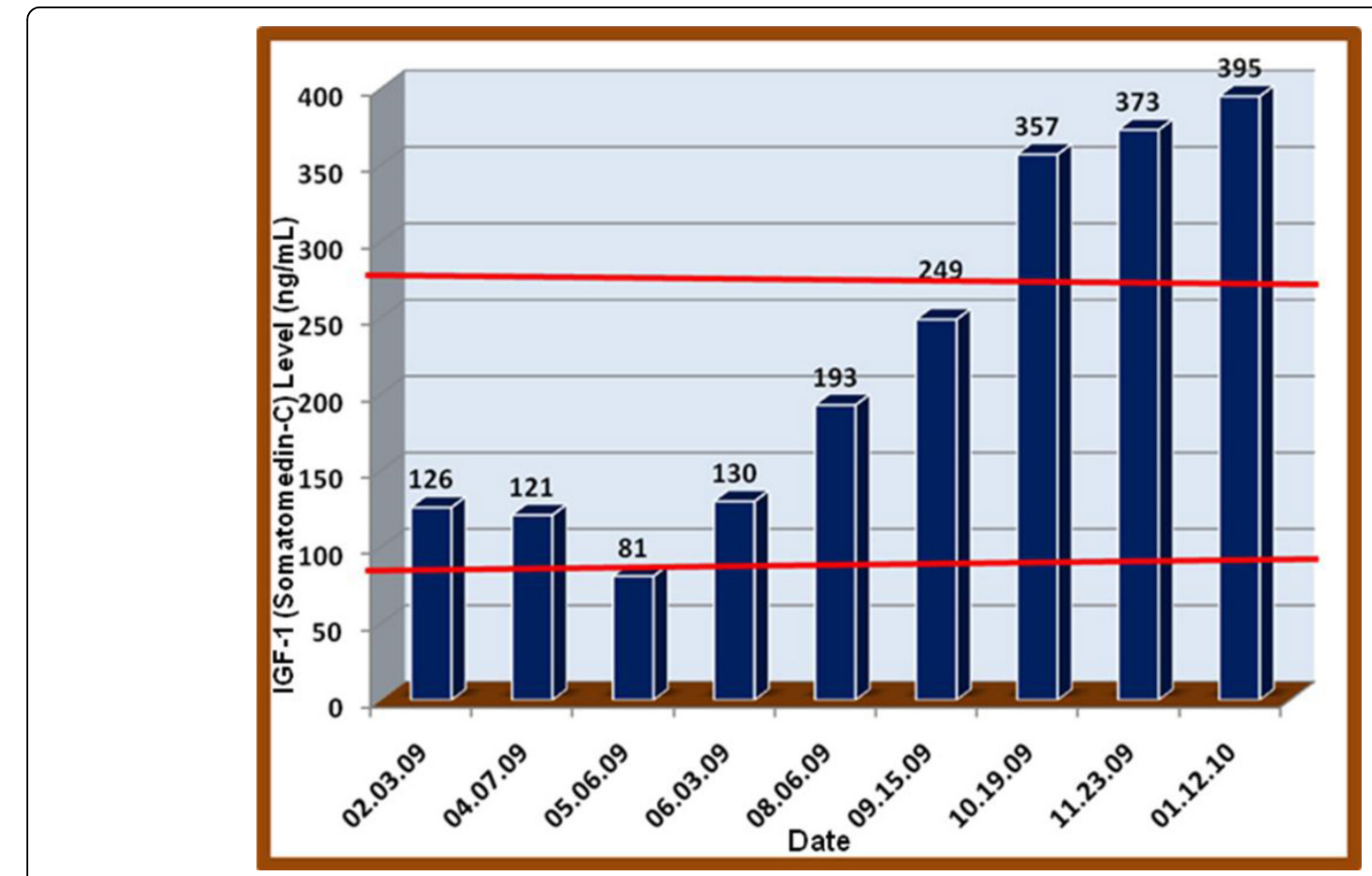

Figure 1 IGF-1 (Somatomedin-C). Reference range: 94 to $267 \mathrm{ng} / \mathrm{mL}$.

increase to a peak concentration of $3.3 \mathrm{ng} / \mathrm{ml}$ as can be observed in Figure 2.

Following this novel combined treatment we observed an improvement in both physiological and neuropsychiatric symptoms.

\section{Discussion}

Adult Growth Hormone Deficiency (AGHD) is marked by a number of neuropsychiatric, cardiac, metabolic, muscular, bone symptoms and clinical features. The most common of these are increased body fat (particularly

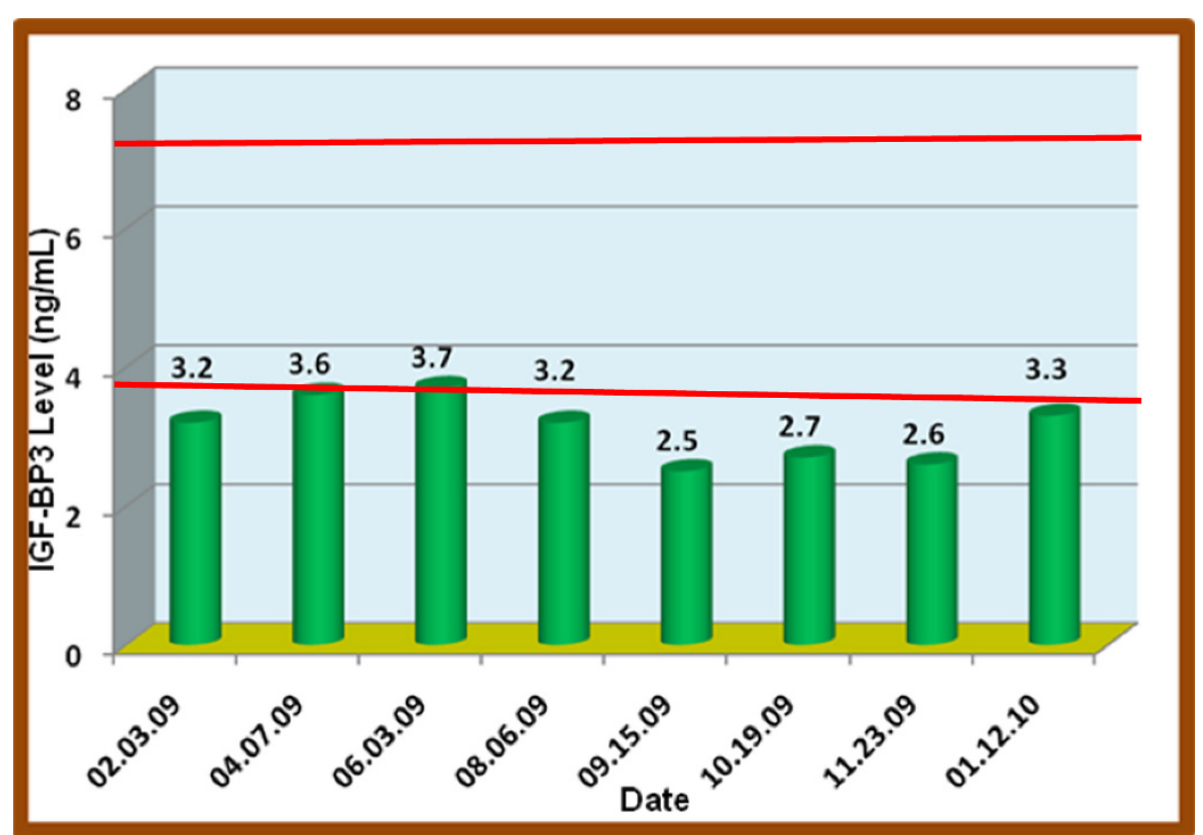

Figure 2 IGF-BP3. Reference range: 3.4 to $7.0 \mathrm{ng} / \mathrm{mL}$. 
abdominal fat), decreased lean body mass (including muscle) and functional strength, thin skin and cool extremities, decreased psychological well-being and energy, reduced bone density, an increase in c-reactive protein, low-density lipoprotein (LDL), fibrinogen, and plasminogen activator inhibitor-1 (PAI-1), a decrease in high-density lipoprotein (HDL), decreased insulin sensitivity, and decreased quality of life [13].

It appears that in some patients with AGHD, IGF-1 elevation is resistant to direct GH treatment. The interaction of IGF-1 and IGF-BP3 is quite complex but seems to involve the integrity of the GH receptor. Previous work from Wilson's laboratory has shown that the constant subcutaneous infusion of IGF-1 to monkeys with normal pituitary glands results in a sustained elevation in circulating concentrations of IGF-BP3, whereas the acute administration of IGF-1 to monkeys pretreated with a GH receptor antagonist produces a brief, but significant, elevation in serum IGF-BP3. Experiments from Wilson's group indicate that IGF-1 administration during GH receptor antagonism restores circulating levels of IGF-BP3. It remains to be determined whether IGF-1 directly affects hepatic synthesis and secretion of IGFBP3 [14]. Therefore the use of IGF-1 alone may not be enough to raise IGF-BP3 levels but in combination with GH receptor agonistic activity it may induce the increases we observed herein.

Finally, we reported earlier from our laboratory [13] on the benefits of increasing low IGF-1 plasma levels to normal values. These benefits, which are consistent with literature findings [15], include an increase of IGF-1 levels to the high normal range; reverses of CMD and BMD from 138.1 to 279.4; fibromyalgia patients showed significant improvement with IGF-1 level of 98.6 to 173.3; brain processing speed and memory improved with IGF-1 levels of 150 to 250; 100-point increase of IGF-1 levels associated with seven-point increases in I. Q.; an IGF-1 elevation of 74.0 to 362.6 in head trauma patients; improved anxiety, depression, and short/long term memory; improvement in cognitive function from 135 to 213; reduced carotid intimal media thickness from 51.8 to 234.4; improvement in insulin sensitivity IGF-1 levels of 103.5 to 231.1; and reduction of abdominal fat accumulation occurring with the increase of IGF-1 from 146 to 267.

\section{Conclusion}

The IGF-BP3 binding protein may not rise with IGF-1 treatment alone. The need for both IGF-1 and IGFBP3 plasma levels to rise especially in cases with AGHD as seen in the case presented herein is adequately supported in the literature. Impairment of this complex system may be overcome by the combination of both GH (using Norditropin ${ }^{\circ}$ ) and IGF-1 (using
Increlex ${ }^{\odot}$ ) and must await further confirmation in a large population.

\section{Consent}

Written informed consent was obtained from the patient for publication of this case report and accompanying images. A copy of the written consent is available for review by the Editor-in-Chief of this journal.

\section{Acknowledgements}

The authors thank the entire PATH Foundation and the clinical and administrative staff for their support and assistance.

\section{Author details}

'Department of Neurological Surgery, Weill Cornell College of Medicine, New York, NY, USA. ${ }^{2}$ Clinical Neuroscience and Population Genetics, Ziv Government Medical Center, Safed, Israel. ${ }^{3}$ Department of Clinical Neurology, PATH Foundation NY, NewYork, NY, USA. ${ }^{4}$ Department of Occupational Safety and Health, Chang Jung Christian University, Taiwan, R. O. C.

${ }^{5}$ Department of Nutrigenomics Reward Deficiency Solutions, LLC, San Diego, CA, USA. ${ }^{6}$ Department of Psychiatry, University of Florida College of Medicine, Gainesville, FL, USA.

\section{Authors' contributions}

All authors actively participated by writing the article and developing graphics and literature citations. All authors read and approved the final manuscript.

\section{Competing interests}

The authors declare that they have no competing interests.

Received: 11 February 2010 Accepted: 15 September 2010

Published: 15 September 2010

\section{References}

1. Svensson J, Tivesten A, Isgaard J: Growth hormone and the cardiovascular function. Minerva Endocrinol 2005, 30:1-13

2. Hubina E, Kovács L, Szabolcs I, Rimanóczy E, Czirják S, Góth M: Serum tumor marker levels during a 12-months growth hormone replacement therapy in patients with adult growth hormone deficiency. Orv Hetil 2002, 143:601-605.

3. De Gennaro Colonna V, Bertola G, Coco CB, Bifano M, Cocchi D, Maggi A, Müller EE: Hypothalamic-pituitary somatotropic function in pre-pubertal hypothyroid rats: effect of growth hormone replacement therapy. Proc Soc Exp Biol Med 1991, 196:432-437.

4. Gelato $M$, McNurlan M, Freedland E: Role of recombinant human growth hormone in HIV-associated wasting and cachexia: pathophysiology and rationale for treatment. Clinical Therapeutics 2007, 29:2269-2288.

5. Humber CE, Tierney JF, Symonds RP, Collingwood M, Kirwan J, Williams C, Green JA: Chemotherapy for advanced, recurrent or metastatic endometrial cancer: a systematic review of Cochrane collaboration. Annals of Oncology 2007, 18:409-420.

6. Maison P, Chanson P: Cardiac effects of growth hormone in adults with growth hormone deficiency: a meta-analysis. Circulation 2003, 108:2648-2652.

7. Kelestimur F: Growth hormone deficiency after traumatic brain injury in adults: when to test and how to treat? Pediatr Endocrinol Rev 2009, 6:534-539.

8. Tritos NA, Biller BM: Growth hormone and bone. Curr Opin Endocrinol Diabetes Obes 2009, 16:415-422.

9. Yuen KC, Bennett RM, Hryciw CA, Cook MB, Rhoads SA, Cook DM: Is further evaluation for growth hormone $(\mathrm{GH})$ deficiency necessary in fibromyalgia patients with low serum insulin-like growth factor (IGF)-I levels? Growth Horm IGF Res 2007, 17:82-88.

10. Van Dam PS: Somatropin therapy and cognitive function in adults with growth hormone deficiency: a critical review. Treat Endocrinol 2006, 5:159-170. 
11. Kooistra HS, Voorhout G, Mol JA, Rijnberk A: Combined pituitary hormone deficiency in German shepherd dogs with dwarfism. Domest Anim Endocrinol 2000, 19:177-190.

12. Braverman ER, Blum K, Kerner M, Kennedy R, Dispensa M, Kern S, Prihoda TJ: Low and low normal IGF-1 levels in patients with Chronic Medical Disorders (CMD) is independent of anterior pituitary deficiencies of LH, FSH and TSH: Implications for treating CMD using I-GF-1 deficiencies as a diagnostic marker. Poster presented at the 91st Annual Meeting of The Endocrine Society, 12 June 2009; Washington, DC.

13. Lasaite $L$, Bunevicius R, Lasiene $D$, Lasas $L$ : Psychological functioning after growth hormone therapy in adult growth hormone deficient patients: endocrine and body composition correlates. Medicina (Kaunas) 2004, 40:740-744.

14. Wilson ME: Insulin-like growth factor I (IGF-I) replacement during growth hormone receptor antagonism normalizes serum IGF-binding protein-3 and markers of bone formation in ovariectomized rhesus monkeys. $J$ Clin Endocrinol Metab 2000, 85:1557-1562.

15. Lo J, You SM, Canavan B, Liebau J, Beltrani G, Koutkia P, Hemphill L, Lee H, Grinspoon S: Low-dose physiological growth hormone in patients with HIV and abdominal fat accumulation: a randomized controlled trial. Journal of American Medical Association 2008, 300:509-519.

doi:10.1186/1752-1947-4-305

Cite this article as: Braverman et al:: Adult growth hormone deficiency treatment with a combination of growth hormone and insulin-like growth factor-1 resulting in elevated sustainable insulin-like growth factor-1 and insulin-like growth factor binding protein 3 plasma levels: a case report. Journal of Medical Case Reports 2010 4:305.

\section{Submit your next manuscript to BioMed Central and take full advantage of:}

- Convenient online submission

- Thorough peer review

- No space constraints or color figure charges

- Immediate publication on acceptance

- Inclusion in PubMed, CAS, Scopus and Google Scholar

- Research which is freely available for redistribution

Submit your manuscript at www.biomedcentral.com/submit 